\title{
Influence of thermomechanical processing parameters on critical temperatures to develop an Advanced High- Strength Steel microstructure
}

\author{
L. F. Romano-Acosta ${ }^{1, *}$ (1), O. García-Rincon², J. P. Pedraza ${ }^{2}$, and E. J. Palmiere ${ }^{1}$ \\ ${ }^{1}$ Department of Materials Science and Engineering, The University of Sheffield, Sir Robert Hadfield Building, Mappin Street, \\ Sheffield S1 3JD, UK \\ ${ }^{2}$ Ternium-Mexico, 66450 San Nicolas de los Garza, Nuevo Leon, Mexico
}

Received: 17 May 2021

Accepted: 12 August 2021

Published online:

27 August 2021

(C) The Author(s) 2021

\begin{abstract}
A good selection of the thermomechanical processing parameters will optimize the function of alloying elements to get the most of mechanical properties in Advanced High-Strength Steels for automotive components, where high resistance is required for passenger safety. As such, critical processing temperatures must be defined taking into account alloy composition, in order for effective thermomechanical processing schedules to be designed. These critical temperatures mainly include the recrystallization stop temperature $\left(T_{5 \%}\right)$ and the transformation temperatures $\left(\mathrm{A}_{\mathrm{r} 1}, \mathrm{~A}_{\mathrm{r} 3}, \mathrm{~B}_{\mathrm{s}}\right.$, etc.). These critical processing temperatures were characterized using different thermomechanical conditions. $T_{5 \%}$ was determined through the softening evaluation on double hit tests and the observation of prior austenite grain boundaries on the microstructure. Phase transformation temperatures were measured by dilatometry experiments at different cooling rates. The results indicate that the strain per pass and the interpass time will influence the most on the determination of $T_{5 \%}$. The range of temperatures between the recrystallized and non-recrystallized regions can be as narrow as $30^{\circ} \mathrm{C}$ at a higher amount of strain. The proposed controlled thermomechanical processing schedule involves getting a severely deformed austenite with a high dislocation density and deformation bands to increase the nucleation sites to start the transformation products. This microstructure along with a proper cooling strategy will lead to an enhancement in the final mechanical properties of a particular steel composition.
\end{abstract}

Handling Editor: P. Nash.

Address correspondence to E-mail: luis.romanoac@hotmail.com 


\section{Introduction}

Advanced High-Strength Steels (AHSS) have been introduced in the automotive industry due to their good combination of ductility and resistance. AHSS family includes transformation induced plasticity (TRIP), twinning induced plasticity (TWIP), martensitic steel, dual phase (DP) and complex phase (CP) steels. All AHSS microstructures are produced through a good control on the thermomechanical processing (TMP) design [1, 2]. The good mechanical properties of AHSS are the result of the refined microstructure. The microstructure typically consists of a combination of ferrite, bainite and martensite, but also in certain conditions, retained austenite and / or pearlite may be present in relatively small amounts [3]. The volume fraction of these phases will depend on the thermomechanical processing route applied to the steel.

Critical processing temperatures, such as the recrystallization stop temperature $\left(T_{5 \%}\right)$ and phase transformation temperatures, are essential parameters to design a successful TMP route. These temperatures are considered critical due to the sensibility they have to alter the final microstructure of the strip after processing, which directly affects the mechanical properties.

In the case of phase transformation temperatures, although the $A_{1}$ and $A_{3}$ equilibrium temperatures are important, from the standpoint of industrial processing with progressively falling temperatures, the $A_{r 1}$ and $A_{r 3}$ are the most relevant. These temperatures will mainly depend on the chemical composition, austenite grain conditioning and cooling rates [4]. These parameters are important for the designing of the TMP schedule because it is recommended to deform while in single phase austenite, due to different properties of ferrite and austenite that can lead to different mechanical properties in different zones of the steel strip transfer bar.

The recrystallization stop temperature $\left(T_{5 \%}\right)$ is defined as the maximum temperature at which no more than $5 \%$ of recrystallization in austenite grains is observed at certain deformation conditions.

Finishing passes of the TMP schedule are recommended to be carried out at temperatures below $T_{5 \%}$ in what is often referred to as controlled rolling to develop high mechanical properties [5]. During controlled rolling, the strain accumulation and associated high dislocation density will increase the nucleation sites for subsequent phase transformations. This temperature will depend on the chemical composition of the steel and the deformation parameters such as the amount of strain, the strain rate and the interpass time.

The finishing passes of a successful TMP schedule should take place in a range of temperatures between $T_{5 \%}$ and $\mathrm{A}_{\mathrm{r} 3}$, where $T_{5 \%}$ is higher than $\mathrm{A}_{\mathrm{r} 3}$. Deformation at temperatures below $T_{5 \%}$ generates a strain accumulation without virtually any recrystallization of austenite. This will produce a larger $S_{\mathrm{v}}$, which is the ratio of grain boundary area per unit volume, causing high driving force and nucleation sites for recrystallization or phase transformation to occur [6]. Besides, at an industrial scale, if the designed the temperature is too high, it would be complex to maintain the strip at that temperature and the austenite might recrystallize. In contrast, if the deformation temperature is too low, the rolling force at the finishing mill will be higher, which will increase the operating costs.

The present work aims to study the effects of TMP parameters of an AHSS to establish the critical temperatures leading to more efficient exploitation of beneficial microstructures and associated mechanical properties. This conducts to the proposal of a suitable processing strategy for hot-rolled AHSS.

\section{Material and methods}

The commercial steel grade used in this research was supplied by Ternium, Mexico, and consisted of a 34-mm-thick plate with the chemical composition reported to be within the ranges listed in Table 1.

The transformation temperatures $\left(\mathrm{A}_{\mathrm{r} 1}\right.$ and $\left.\mathrm{A}_{\mathrm{r} 3}\right)$ were identified through the measurement of length change during heat treatment on large-scale dilatometry specimens. The equipment used for the measurements was a purpose-built thermal processing unit at The University of Sheffield, capable of controlled heating and/or cooling while continuously measuring the changes in length, similar to traditional dilatometry instruments. However, these dilatometry specimens were cylindrical bars of $12 \mathrm{~mm}$ diameter by $155 \mathrm{~mm}$ length with a $1.6 \mathrm{~mm}$ diameter hole in the center to place a K-type thermocouple. The bars were heated up to $1000{ }^{\circ} \mathrm{C}$, at a rate of $10^{\circ} \mathrm{Cs}^{-1}$, held for $3 \mathrm{~min}$ and then cooled to 
Table 1 Maximum chemical composition in wt.\%

\begin{tabular}{llllllllll}
\hline $\mathrm{C}$ & $\mathrm{Mn}$ & $\mathrm{Al}$ & $\mathrm{Si}$ & $\mathrm{P}$ & $\mathrm{S}$ & $\mathrm{Cu}$ & $\mathrm{Ni}$ & $\mathrm{Cr}+\mathrm{Mo}+\mathrm{Ni}$ & $\mathrm{V}+\mathrm{Nb}+\mathrm{Ti}$ \\
\hline 0.25 & 1.9 & 0.04 & 0.20 & 0.08 & 0.015 & 0.20 & 0.50 & $0.25-0.50$ & $0.05-0.15$ \\
\hline
\end{tabular}

room temperature at different cooling rates of $0.1,1$, 10 and $20^{\circ} \mathrm{C} \mathrm{s}^{-1}$. These parameters were chosen to ensure the austenite microstructure, trying to homogenize the temperature along the bar and minimize the effect of grain coarsening of the specimen. The $A_{r 3}$ and $A_{r 1}$ were determined by the change of the slope on the displacement during the cooling. Additionally, JMatPro®Version 9.0 software was used to calculate the $A_{1}$ and $A_{3}$ equilibrium temperatures and also to get the CCT diagram of the steel [7].

The recrystallization stop temperature $\left(T_{5 \%}\right)$ can be estimated by analysis of double hit tests [8-10]. Double hit flow stress curves enable for the determination of static restoration occurring between deformation passes. Dutta and Palmiere [9] have demonstrated that the softening of the material is directly related to $T_{5 \%}$. In this research, the double hit test consists of deforming a plane strain compression (PSC) specimen over two passes at the same deformation temperature and the same amount of strain and strain rate at a known interpass time.

PSC testing closely replicates the material flow of the hot rolling process [11]. Double hit deformations were performed on a thermomechanical compression (TMC) machine. This servo-hydraulic machine has outstanding control of the processing parameters such as deformation temperature, strain, strain rate and interpass time, and any commercial TMP design can be replicated. More detail of the TMC machine used for PSC double hit tests can be found in the following sources [11-14].

PSC specimens had dimensions of $60 \mathrm{~mm} \times 30$ $\mathrm{mm} \times 10 \mathrm{~mm}$ where the $60 \mathrm{~mm}$ is parallel to the rolling direction and $10 \mathrm{~mm}$ is the initial thickness. Double hit tests were performed following the TMP route shown in Fig. 1. $T_{5 \%}$ was evaluated for different deformation parameters through double hit test by looking at various deformation temperatures, varying the strain per pass and two different interpass time as specified in Table 2. Parameters of set 3 are representative of the initial deformation on the finishing mill in the industrial process.

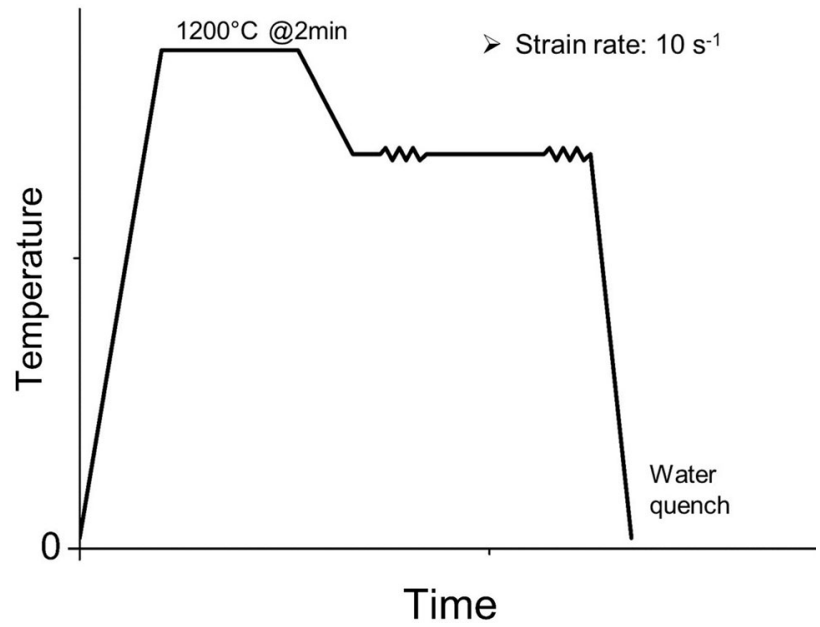

Figure 1 Schematic schedule of double hit tests.

The softening percentage calculated in between the two passes is related to the recrystallization fraction. Softening percentage for each test was calculated by different methods: $2 \%$ and $5 \%$ strain method [8], the area under the flow stress curve [15] and the offset $2 \%$ method [16]. However, this work will only show calculations of the $2 \%$ offset strain method since this had the best correlation for all deformation sets. The completely elongated morphology of the prior austenite grains observed in the microstructure validated the $T_{5 \%}$ for the three sets of deformation parameters as this indicates that no recrystallization took place. Prior austenite grain boundaries were revealed by etching with an aqueous saturated picric acid solution after the standard metallographic preparation. PSC specimens were cut to observe the longitudinal plane at the center of the deformation.

\section{Results and discussion}

\section{Phase transformation temperatures}

Table 3 shows a summary of phase transformation temperatures at different cooling rates. As the heating rate on every test was set to $10{ }^{\circ} \mathrm{C} \mathrm{s}^{-1}$, the $\mathrm{A}_{\mathrm{c} 1}$ and $\mathrm{A}_{\mathrm{c} 3}$ were measured and defined as $790{ }^{\circ} \mathrm{C}$ and $842{ }^{\circ} \mathrm{C}$, respectively. The real cooling rate was 
Table 2 Deformation parameters for different sets of double hit tests

\begin{tabular}{llll}
\hline & Set 1 & Set 2 & Set 3 \\
\hline Strain per pass & 0.25 & 0.25 & 0.40 \\
Interpass time & $20 \mathrm{~s}$ & $4 \mathrm{~s}$ & $4 \mathrm{~s}$ \\
Deformation Temperature $\left({ }^{\circ} \mathrm{C}\right)$ & $920,950,980,1000$ & $980,1000,1020$ & 950,980 \\
\hline
\end{tabular}

\begin{tabular}{lllllll}
\hline Cooling rate & $\mathrm{A}_{\mathrm{r} 1}\left({ }^{\circ} \mathrm{C}\right)$ & $\mathrm{A}_{\mathrm{r} 3}\left({ }^{\circ} \mathrm{C}\right)$ & \multicolumn{2}{l}{ Measured Cooling rate } & \multicolumn{2}{l}{ Calculated $\mathrm{A}_{\mathrm{r} 3}\left({ }^{\circ} \mathrm{C}\right)$} \\
\cline { 5 - 7 } & & & & Mintz' & Yuan' & JMatPro \\
\hline $0.1{ }^{\circ} \mathrm{C} \mathrm{s}^{-1}$ & 674 & 755 & $0.1{ }^{\circ} \mathrm{C} \mathrm{s}^{-1}$ & 653 & 837 & 791 \\
$1 \mathrm{C} \mathrm{s}^{-1}$ & 604 & 710 & $1{ }^{\circ} \mathrm{C} \mathrm{s}^{-1}$ & 647 & 771 & 753 \\
$10^{\circ} \mathrm{C} \mathrm{s}^{-1}$ & 480 & 672 & $9.88{ }^{\circ} \mathrm{C} \mathrm{s} \mathrm{s}^{-1}$ & 584 & 686 & 597 \\
$20^{\circ} \mathrm{C} \mathrm{s}^{-1}$ & 496 & 641 & $14.12{ }^{\circ} \mathrm{C} \mathrm{s} \mathrm{s}^{-1}$ & 514 & 657 & 502 \\
\hline
\end{tabular}

Table 3 Summary of dilatometry tests at different cooling rates

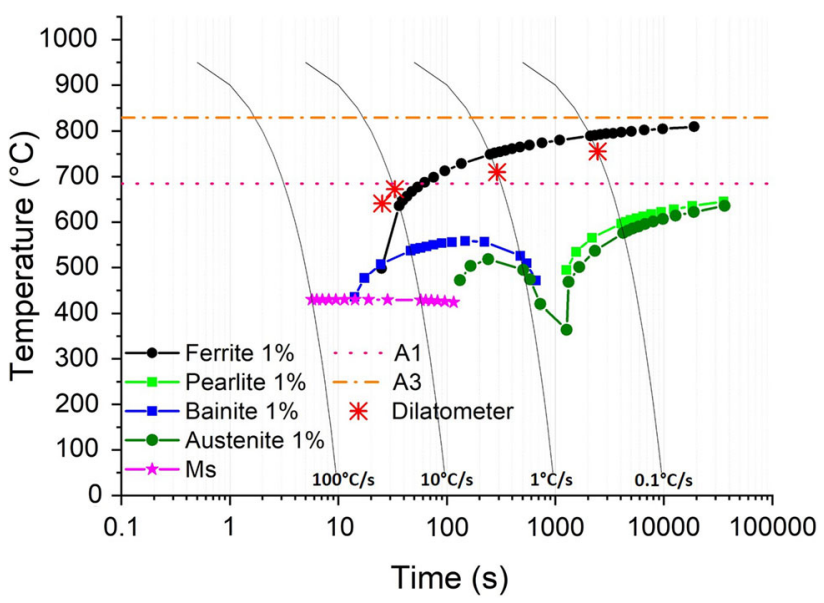

Figure 3 CCT diagram from JMatPro ${ }^{\circledR}$ for the AHSS. Austenitization temperature: $1000{ }^{\circ} \mathrm{C}$, PAGS: $45 \mu \mathrm{m}$. Asterisks represent actual dilatometry measurements.

$\mathrm{A}_{3}$ for thermodynamic conditions. JMatPro ${ }^{\circledR}$ found $665{ }^{\circ} \mathrm{C}$ and $832{ }^{\circ} \mathrm{C}$ as $\mathrm{A}_{1}$ and $\mathrm{A}_{3}$, respectively, while Thermo-Calc ${ }^{\circledR}$ indicates that the $\mathrm{A}_{1}$ is $665{ }^{\circ} \mathrm{C}$ and $\mathrm{A}_{3}$ is $835{ }^{\circ} \mathrm{C}$. The microstructure in Fig. 2 shows an equiaxed austenite structure with a grain size of $46 \pm 5.7 \mu \mathrm{m}$ and represents the condition of the dilatometry specimens before cooling. The continuous cooling transformation (CCT) diagram shown in Fig. 3 was calculated with the JMatPro ${ }^{\circledR}$ software using the dilatometer specimen conditions of austenitization temperature set to $1000{ }^{\circ} \mathrm{C}$ and prior austenite grain size (PAGS) of $45 \mu \mathrm{m}$. Dilatometry data were added to the CCT diagram as asterisks.
Figure 2 PAGB of AHSS dilatometry specimen before cooling. PAGS $=46 \pm 5.7 \mu \mathrm{m}$. Etchant: Aqueous picric acid solution. 


\section{Set 2}
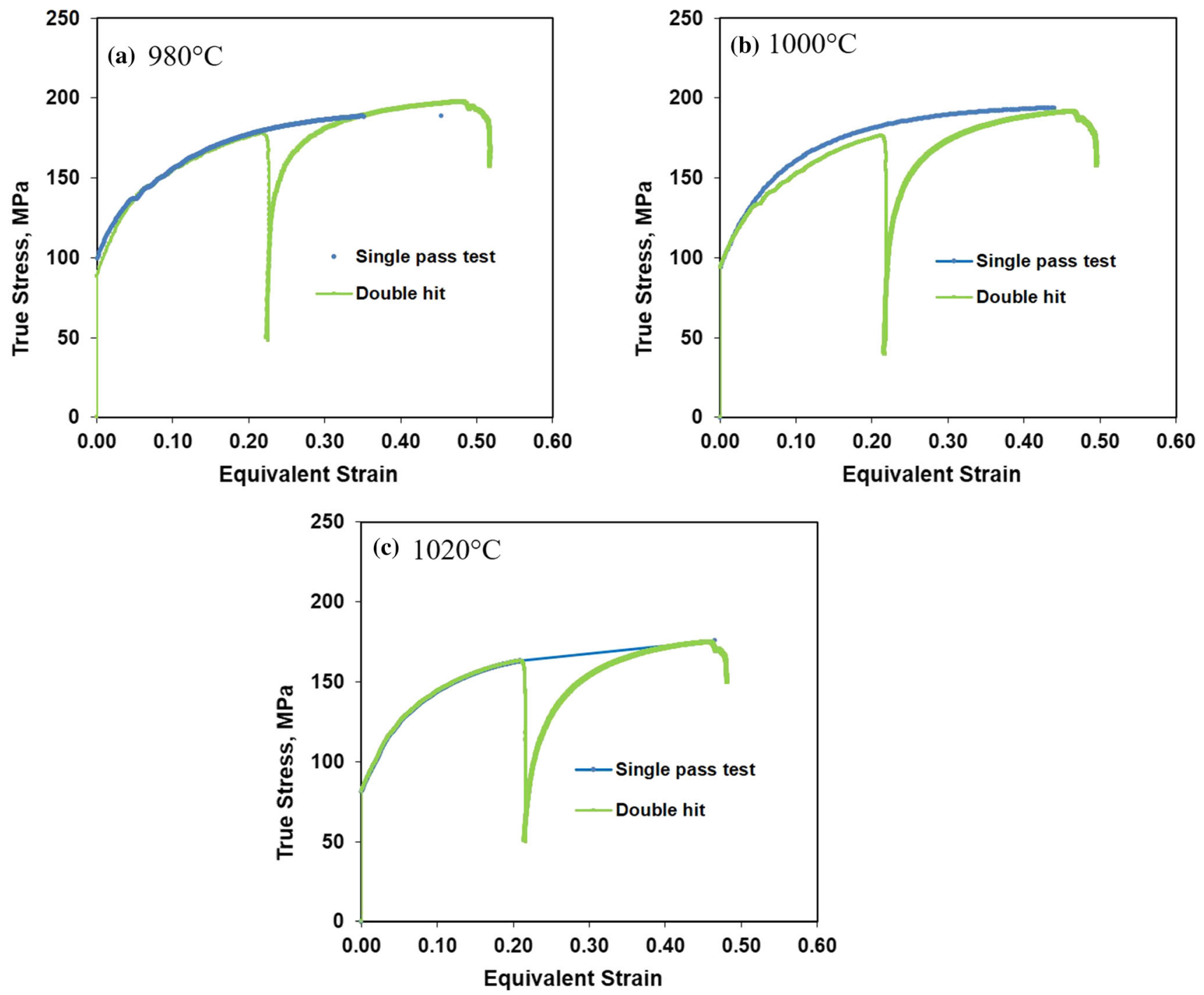

Figure 4 Flow stress curves of double hit tests of set 2 at a $980{ }^{\circ} \mathrm{C}, \mathbf{b} 1000{ }^{\circ} \mathrm{C}$ and c $1020{ }^{\circ} \mathrm{C}$.

This shows that the $A_{r 3}$ temperatures predicted by JMatPro ${ }^{\circledR}$ are a good approach to the $A_{\mathrm{r} 3}$ measured in the dilatometer for different cooling rates.

\section{Recrystallization stop temperature $\left(T_{5 \%}\right)$}

The macroscopic flow stress behavior of the double and single hit tests corresponding to deformation parameters of sets 2 and 3 is shown in Figs. 4 and 5, respectively. These curves were created from load versus displacement data following the best practice developed by Loveday et al. [11, 20]. The initial stress value in each test is an indicator of the yield stress at that specific temperature. At higher temperatures, less load is required for the material to flow [21]. The maximum stress of tests at $1000{ }^{\circ} \mathrm{C}$ is about $200 \mathrm{MPa}$, whereas at $920{ }^{\circ} \mathrm{C}$ the maximum stress in the curve is up to $250 \mathrm{MPa}$.

The data of single pass of set 2 at $980{ }^{\circ} \mathrm{C}$ and $1000{ }^{\circ} \mathrm{C}$ were taken from the single-pass tests of set 1 , while on the $1020^{\circ} \mathrm{C}$, the single pass was extrapolated from the first pass of the double hit test.

The deformation parameters of set 3 are the closest to the conditions used in industrial practice. Singlepass tests of set 3 were done for a total strain of 0.40 instead of 0.80 . After the deformation, the specimens were held at the deformation temperature for $4 \mathrm{~s}$ followed by water quench. However, the flow stress 
Set 3
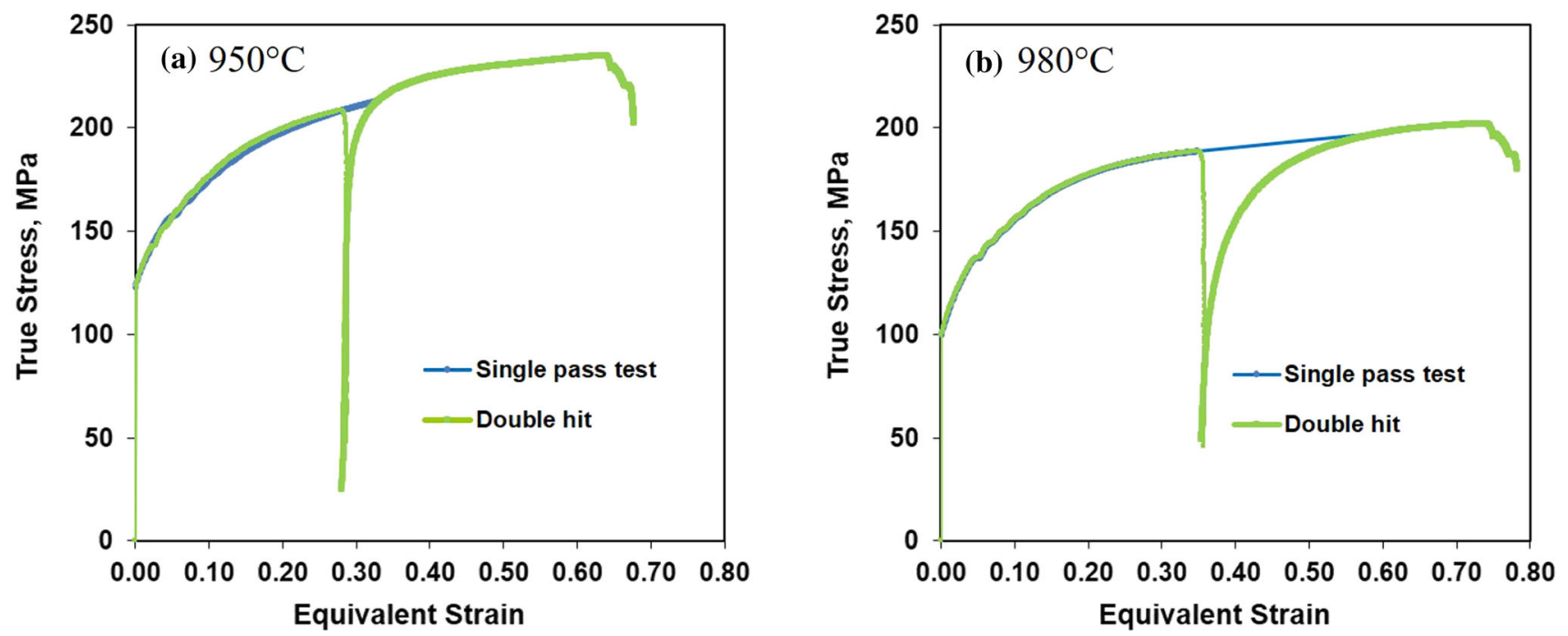

Figure 5 Flow stress curves of double hit tests of set 3 at a $950{ }^{\circ} \mathrm{C}$ and b $980{ }^{\circ} \mathrm{C}$.

curves of single-pass deformations at $980{ }^{\circ} \mathrm{C}$ and $950{ }^{\circ} \mathrm{C}$ were extrapolated from the first pass of the double hit test for the softening calculations.

The overall softening on double hit tests is an indicator of the deformed state of the prior austenite grains. Due to the relatively low stacking fault energy of austenite, some authors [15, 22] have correlated a value of $20 \%$ overall softening with $T_{5 \%}$, and $60 \%$ overall softening to $T_{95 \%}$, that is the minimum temperature at which fully recrystallized austenite microstructure is present at certain deformation conditions.

The softening percentage calculations are plotted in Fig. 6 for different deformation temperatures of sets

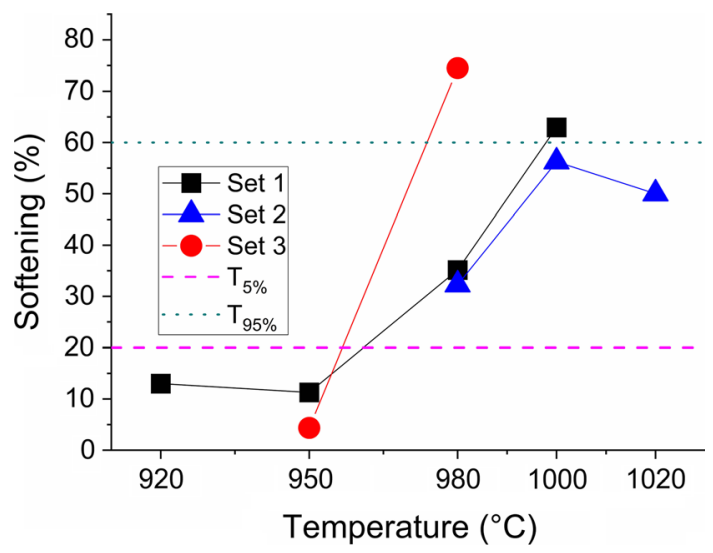

Figure 6 Fraction softening calculated by the $2 \%$ offset strain method for set 1 , set 2 and set 3 deformation conditions. $T_{5 \%}$ and $T_{95 \%}$ are represented as 20 and $60 \%$ softening.
1, 2 and 3. Softening calculations for sets 1 and 3 suggest that at $950{ }^{\circ} \mathrm{C}$, the austenite grain shape would be completely elongated as their softening values are less than $20 \%$. In the case of $980{ }^{\circ} \mathrm{C}$, the softening calculated for set 1 and 2 is in between $T_{5 \%}$ and $T_{95 \%}$. This means that partial recrystallized structure is expected. On the other hand, the overall softening at $980{ }^{\circ} \mathrm{C}$ for set 3 is higher than the softening established for $T_{95 \%}$. The larger amount of deformation causes a larger driving force that encourages recrystallization. Because of that, deformation conditions of set 3 at $980{ }^{\circ} \mathrm{C}$ would indicate a fully recrystallized structure of the austenite. This would also apply to deformations of set 1 at $1000{ }^{\circ} \mathrm{C}$.

The flow stress of the second pass of double hit tests after shorter interpass, as in the case of set 3 , would tend to be closer to the flow stress of the single hit test at the same level of strain. Hence, the softening decreases on the second pass and the recrystallization would need more energy (thermal or mechanical) to take place $[22,23]$.

As a validation of the measured softening behavior, the prior austenite grain was characterized for each of the deformed specimens of double and single hit tests. Microstructure observation confirmed the prediction of the austenite grains shape analyzed by the softening of double hit tests. Figures 7, 8 and 9 show the microstructure of prior austenite grain boundaries of sets 1, 2 and 3, respectively. The microstructure details, grain shape and amount of 

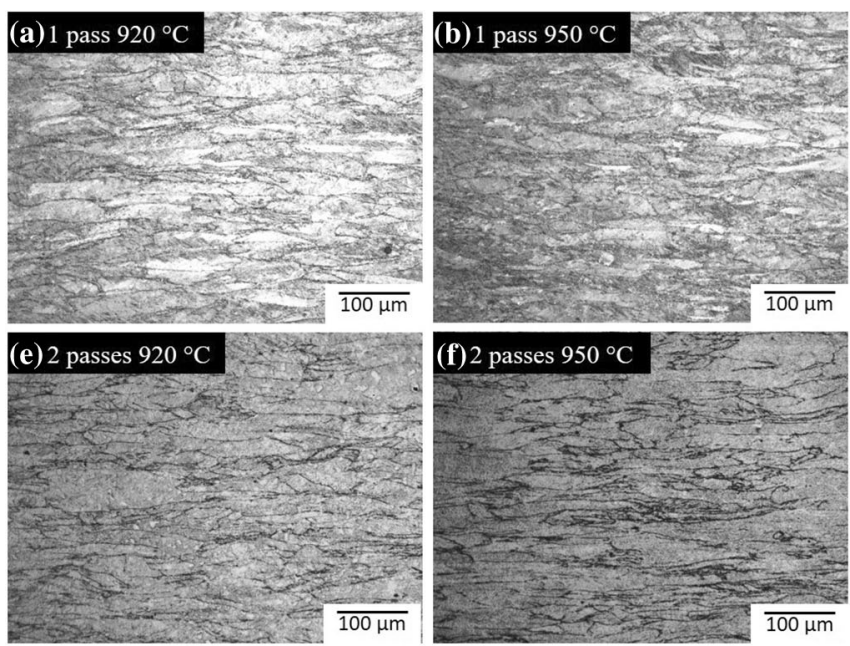
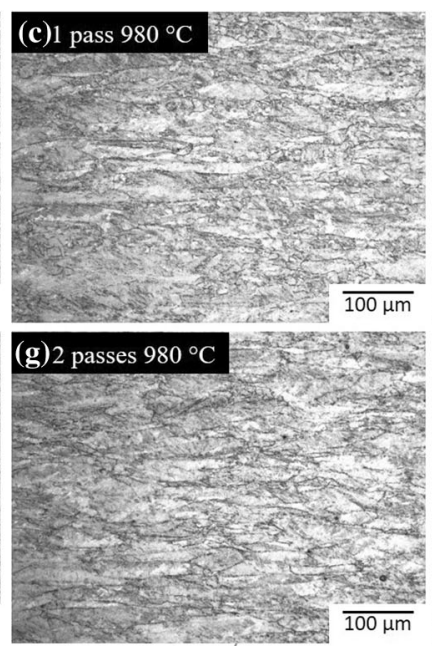
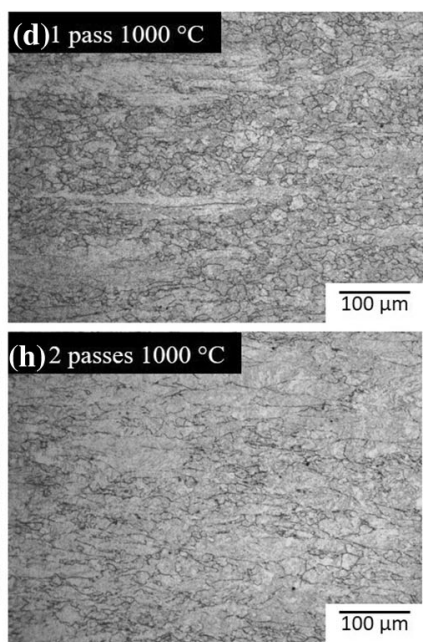

Figure 7 Prior austenite grain boundaries of single-pass (a-d) and double hit tests (e-h) deformed specimens at (a and e) $920{ }^{\circ} \mathrm{C}$, (b and f) $950{ }^{\circ} \mathrm{C}$, (c and g) $980{ }^{\circ} \mathrm{C}$ and (d and h) $1000{ }^{\circ} \mathrm{C}$.
Deformation parameters of set 1: total strain 0.5 , interpass time $20 \mathrm{~s}$, strain rate $10 \mathrm{~s}^{-1}$.
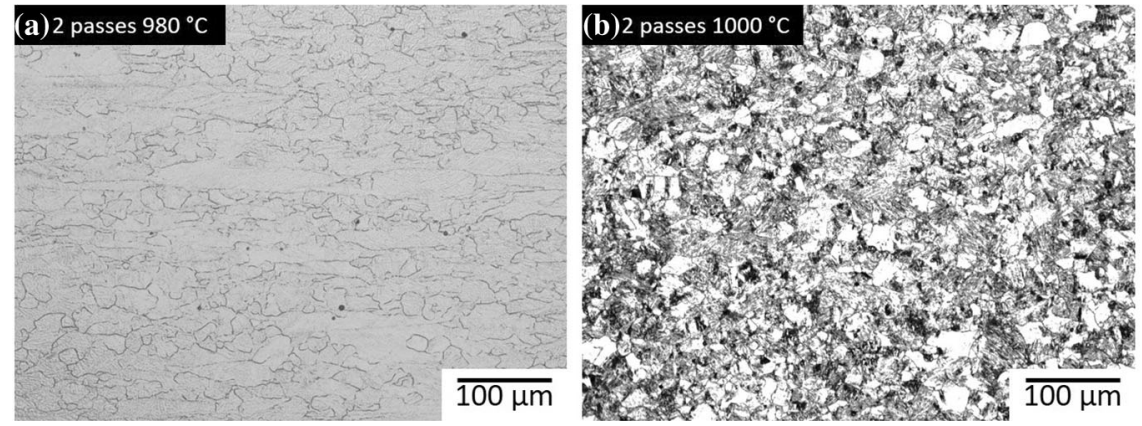

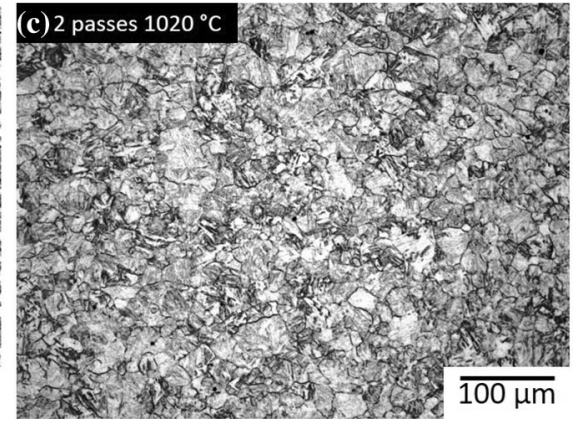

Figure 8 Prior austenite grain boundaries of double hit tests at $\mathbf{a} 980{ }^{\circ} \mathrm{C}, \mathbf{b} 1000{ }^{\circ} \mathrm{C}$ and $\mathbf{c} 1020{ }^{\circ} \mathrm{C}$. Deformation parameters of set 2: total strain 0.5 , interpass time $4 \mathrm{~s}$, strain rate $10 \mathrm{~s}^{-1}$.

recrystallized fraction of the single and double hit tests are summarized in Table 4 . The fraction of recrystallized and non-recrystallized grains was measured following point count method in the standard ASTM E562-19 [24].

The average distance in between the PAGB caused by an accumulated strain of 0.5 in the non-recrystallized conditions is $20 \mu \mathrm{m}$ in the direction perpendicular to the rolling and $80 \mu \mathrm{m}$ parallel to the rolling direction, resulting in a grain aspect ratio of 4 .

The specimens in set 1 of single and double hit tests at $920{ }^{\circ} \mathrm{C}$ and $950{ }^{\circ} \mathrm{C}$ and double hit at $980{ }^{\circ} \mathrm{C}$ show a completely elongated austenite grain. The partial recrystallization structure is present in the single pass at $980{ }^{\circ} \mathrm{C}, 1000{ }^{\circ} \mathrm{C}$ and double hit $1000^{\circ} \mathrm{C}$. Even though the softening on the $1000{ }^{\circ} \mathrm{C}$ of set 1 was around $63 \%$, the microstructure still shows some elongated grains. The non-recrystallized fraction in this condition does not exceed $50 \%$. Since there is a higher percentage of recrystallized fraction when the deformation is done in a single pass at the same total strain, it is thought that the recrystallization occurs after the deformation before the water quench; this period is around $1 \mathrm{~s}$. There are no signs of dynamic recrystallization in the behavior of the flow stress curve. The same situation was observed in the specimen deformed at $1000{ }^{\circ} \mathrm{C}$. Although the single and double hit samples at $1000{ }^{\circ} \mathrm{C}$ have the same total strain of 0.5 , the recrystallized fraction differs. On the double hit test at $1000{ }^{\circ} \mathrm{C}$, some grains may undergo static recovery or have recrystallized during the $20 \mathrm{~s}$ of interpass time after the first pass. The recrystallized fraction in double hit tests is less than the single pass because the static recovery started during the $20 \mathrm{~s}$ of interpass time. During recovery, there is a rearrangement of dislocations which causes no 

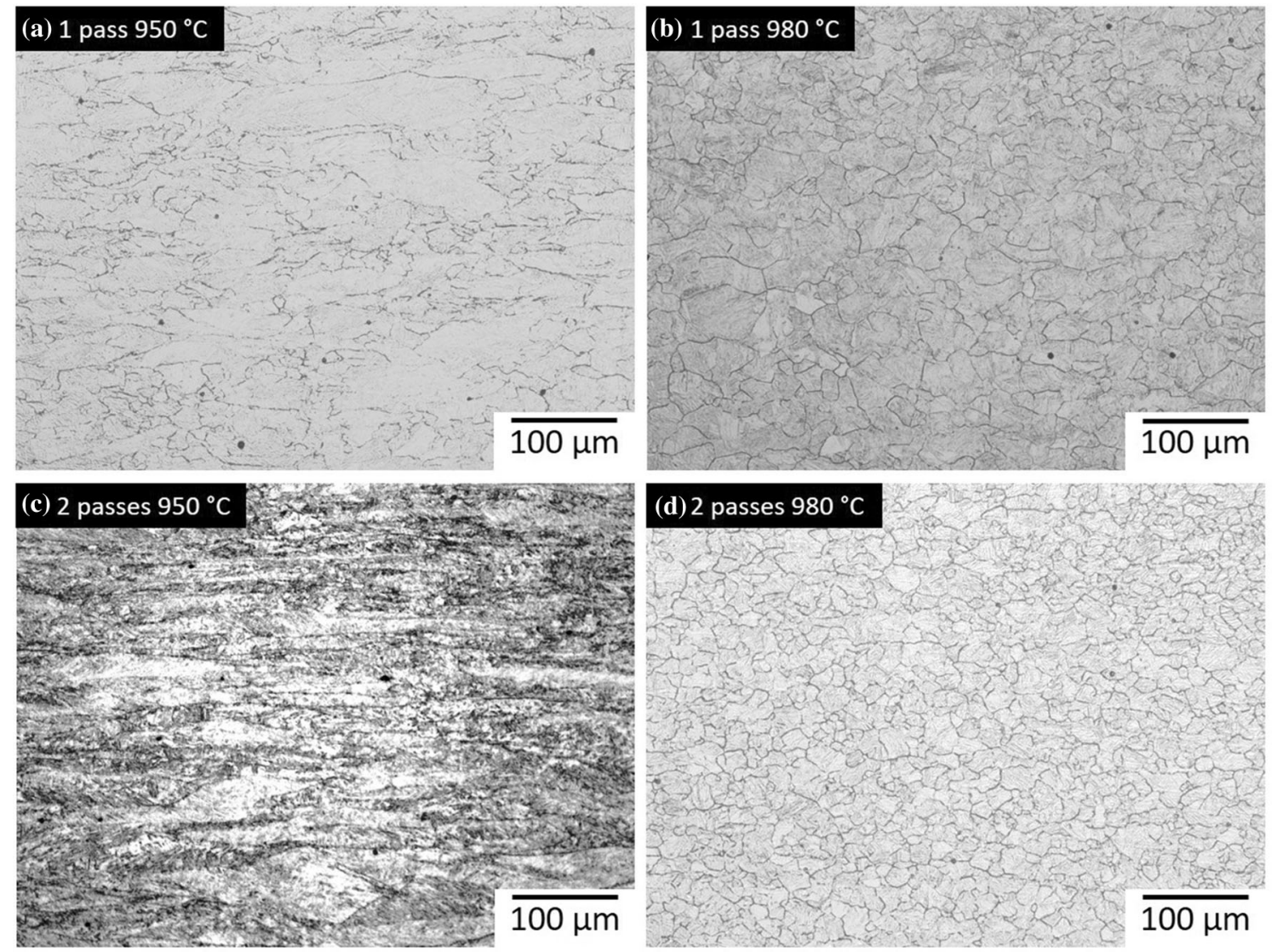

Figure 9 Prior austenite grain boundaries of single-pass (a and b) and double hit tests (c and d) at (a and $\mathbf{c}) 950{ }^{\circ} \mathrm{C}$ and $(\mathbf{b}$ and $\mathbf{d}) 980{ }^{\circ} \mathrm{C}$. Deformation parameters of set 3: strain per pass 0.4 , interpass time $4 \mathrm{~s}$, strain rate $10 \mathrm{~s}^{-1}$.

Table 4 Prior austenite grains microstructure of single and double hit tests

\begin{tabular}{|c|c|c|c|}
\hline Deformation parameters & Deformation Temperature & Single-pass test & Double hit test \\
\hline \multirow[t]{4}{*}{ Set 1} & $1000^{\circ} \mathrm{C}$ & Partial recrystallization $(50 \%)$ & Partial recrystallization $(33 \%)$ \\
\hline & $980^{\circ} \mathrm{C}$ & Partial recrystallization $(22 \%)$ & Non-recrystallized \\
\hline & $950{ }^{\circ} \mathrm{C}$ & Non-recrystallized & Non-recrystallized \\
\hline & $920^{\circ} \mathrm{C}$ & Non-recrystallized & Non-recrystallized \\
\hline \multirow[t]{3}{*}{ Set 2} & $1020^{\circ} \mathrm{C}$ & - & Fully recrystallized \\
\hline & $1000^{\circ} \mathrm{C}$ & - & Fully recrystallized \\
\hline & $980{ }^{\circ} \mathrm{C}$ & - & Partial recrystallization $(19 \%)$ \\
\hline \multirow[t]{2}{*}{ Set 3} & $980{ }^{\circ} \mathrm{C}$ & Fully recrystallized & Fully recrystallized \\
\hline & $950{ }^{\circ} \mathrm{C}$ & Partial recrystallization $(17 \%)$ & Partial recrystallization $(8 \%)$ \\
\hline
\end{tabular}

further recrystallization to happen. This behavior was also reported by Lin et al. [10] who used similar testing conditions varying interpass time from 1 to $100 \mathrm{~s}$.

Despite that the softening percentage calculated for set 2 at temperatures of $1000{ }^{\circ} \mathrm{C}$ and $1020{ }^{\circ} \mathrm{C}$ suggests that the morphology of the austenitic grain should be partially recrystallized, the microstructures show a completely equiaxed grain shape with PAGS of $14 \mu \mathrm{m}$ and aspect ratio of 1.2 . In set 2 , it is until deformations at $980{ }^{\circ} \mathrm{C}$ that partial recrystallized structure is observed. By comparing the double hit tests at $980{ }^{\circ} \mathrm{C}$ of set 1 and 2, it is observed that for a shorter interpass time, there is a higher percentage of 
recrystallized fraction; this is because there is not enough time for the dislocations rearrangement or that the process of static recovery is not completed. This causes strain accumulation after the second pass which encourages recrystallization to take place.

One way to decrease $T_{5 \%}$ is by increasing the strain per pass, as was observed by comparing the double hit tests of set 2 and set 3 . This is because more energy is supplied to the material and the conditions become preferable to start the process of any softening mechanism or recrystallization. Further, the temperature range between $T_{5 \%}$ and $T_{95 \%}$ becomes narrow, being as close as $30{ }^{\circ} \mathrm{C}$ at deformation conditions of set 3 . These data are comparable to the results of Dutta and Palmiere [9] who used a similar steel composition.

\section{Proposed TMP route}

The austenite grain size and shape, which exist immediately prior to transformation, play an important role in the final mechanical properties of the steel. It is well known that grain refinement increases the strength of the material [25].

The TMP route that makes the most of the chemical composition would be by refining the austenite grain and also that the deformation in the finishing mill takes place in between $T_{5 \%}$, to avoid austenite recrystallization, and $\mathrm{A}_{\mathrm{r} 3}$ to avoid deformation of ferrite, thus resulting in strain accumulation and formation of deformation bands with high dislocation density, as well as an increase in nucleation sites for transformation products. This would achieve the best final mechanical properties. Cabibbo et al. [5] have found an increment on impact toughness of different steel compositions through deformations in the non-recrystallization temperature range.

The challenge in the development of AHSS microstructure is to design the cooling strategy [26]. This depends on the dimensions and capacity of the run-out table after the finishing rolling. The higher $\mathrm{A}_{\mathrm{r} 3}$ found at a slow cooling rate was $755^{\circ} \mathrm{C}$; this would suggest that the start temperature on the runout table should be at least this temperature. Considering the deformation parameters of set 3 , which are high deformation in the first pass of the finishing rolling and that the subsequent pass takes place after $4 \mathrm{~s}, T_{5 \%}$ was identified to be $950{ }^{\circ} \mathrm{C}$ by softening fraction of double hit and austenite microstructure observation. The TMP design for the composition and deformation parameters of this AHSS should have a maximum temperature on the first stand of finishing mill of $950{ }^{\circ} \mathrm{C}$. It is expected that during the interpass time, the temperature of the strip decreases, which decreases the driving force for recrystallization for the following pass. Nevertheless, it is recommended to reduce the equivalent strain in each of the subsequent passes. The temperature in the last pass of the rolling mill should be higher than $755^{\circ} \mathrm{C}$ to ensure austenite deformation.

The desired phase volume fractions in the AHSS are obtained by designing a cooling strategy on the run-out table. It is worth mentioning that the austenite condition shown in Fig. 2 is not representative of the austenite at the entrance of the run-out table. The TMP schedule following the deformation passes below $T_{5 \%}$ will produce a larger $S_{\mathrm{v}}$, increasing the nucleation sites for phase transformation [27]. Thus, the CCT curve would shift to the left, which enables the phase transformation to ferrite even while cooling at high cooling rates, as shown in Fig. 10. In order to get a considerable amount of bainite, which is a strong phase with greater ductility than martensite, it is recommended to hold the temperature for a short time at bainite transformation temperatures, which according to the CCT in Fig. 10 for this steel composition is around $450-550{ }^{\circ} \mathrm{C}$.

In actual industrial practice, the reductions in every stand of the mill will be defined depending on the initial and final strip thickness. A thinner thickness strip would require higher strain per pass; consequently, the $T_{5 \%}$ will be lowered after the first pass.

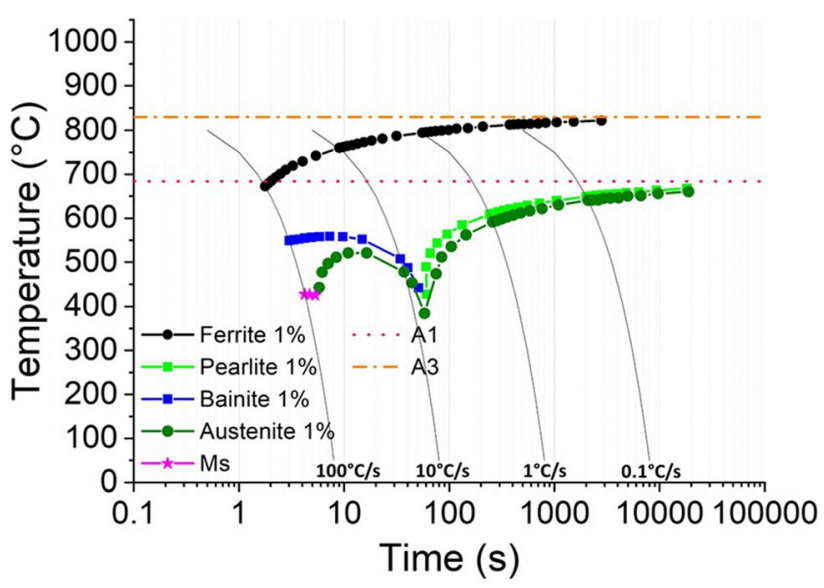

Figure 10 CCT diagram from JMatPro ${ }^{\circledR}$ for the AHSS corresponding to the condition at the entrance of the run-out table after deformation. Austenitization temperature: $850{ }^{\circ} \mathrm{C}$, PAGS: $3 \mu \mathrm{m}$. 
Also, the strain accumulation and hence the $S_{\mathrm{v}}$ at the end of the finishing rolling may be slightly different. This could modify the CCT diagram at the entrance of the run-out table, and a new cooling strategy needs to be designed to get the AHSS microstructure.

\section{Conclusions}

The major findings of this investigation on the thermomechanical processing of AHSS are listed below.

- Critical processing temperatures, such as $A_{1}, A_{3}$ and $T_{5 \%}$, are necessary to design a successful thermomechanical route. For AHSS, the temperature in the last pass of the thermomechanical rolling schedule should be higher than $A_{r 3}$ to ensure austenite deformation but low enough to avoid recrystallization. This results in an austenite pancaked structure with a high $S \mathrm{v}$, which is optimal to enhance the final mechanical properties.

- Microstructural analysis of the prior austenite grains from double hit tests is the most trustful method to detect the presence of recrystallization after a deformation pass. The fraction of softening in between the two passes gives an indication of the shape of the parent austenite at the specified deformation conditions.

- The $T_{5 \%}$ is highly influenced by the processing parameters (strain, strain rate, interpass time). $T_{5 \%}$ can decrease by different factors such as increasing the amount of strain per pass or by maintaining long interpass times.

- Microstructures and softening indicate that $T_{5 \%}$ for set 1 was $980{ }^{\circ} \mathrm{C}$. For the deformation conditions of set 3 , this parameter decreased to $950{ }^{\circ} \mathrm{C}$ due to the effect of a shorter interpass time and a higher amount of strain. This indicates that a strict control of the processing parameters is required to successfully condition the austenite microstructure. Set 3 deformation parameters are also more representative of industrial practice.

- For the steel composition in this research, the highest $\mathrm{Ar}_{3}$ measured at the lowest cooling rate $\left(0.1^{\circ} \mathrm{Cs}^{-1}\right)$ was $755^{\circ} \mathrm{C}$. Then, as the $T_{5 \%}$ for this steel was measured to be $950{ }^{\circ} \mathrm{C}$, this means that the processing window for this steel is $195^{\circ} \mathrm{C}$, which provides great flexibility between mill force capability and control of austenite microstructure prior to transformation.

- A proper TMP route design, as well as the good control in the process, is undoubtedly the crucial part to take advantage of the microalloying elements. A successful TMP route will develop the best mechanical properties controlling the desired amount of phase fractions.

\section{Acknowledgements}

The authors would like to acknowledge to Ternium S.A. for the financial support and material supplied to carry out this research. The corresponding author would also thank CONACYT (National Council of Science and Technology) and the Roberto Rocca Education Program for the financial support.

\section{Authors contribution}

LFRA involved in formal analysis, methodology, investigation, writing-original draft; OGR took part in conceptualization, validation, resources; JPP participated in conceptualization, validation, resources; EJP involved in formal analysis, supervision, writing-review, and editing.

\section{Funding}

The authors declare that they have no known competing financial interests or personal relationships that could have appeared to influence the work reported in this paper.

Open Access This article is licensed under a Creative Commons Attribution 4.0 International License, which permits use, sharing, adaptation, distribution and reproduction in any medium or format, as long as you give appropriate credit to the original author(s) and the source, provide a link to the Creative Commons licence, and indicate if changes were made. The images or other third party material in this article are included in the article's Creative Commons licence, unless indicated otherwise in a credit line to the material. If material is not included in the article's Creative Commons licence and your intended use is not permitted by statutory regulation or exceeds the 
permitted use, you will need to obtain permission directly from the copyright holder. To view a copy of this licence, visit http://creativecommons.org/licen ses/by/4.0/.

\section{References}

[1] Cheah LW (2010) Cars on a diet: the material and energy impacts of passenger vehicle weight reduction in the U.S., Degree of Doctor of Philosophy in Engineering Systems, Engineering Systems Division, Massachusetts Institute of Technology

[2] Gan W, Babu S, Kapustka N, Wagoner R (2006) Microstructural effects on the springback of advanced highstrength steel. Metall Trans A 37(11):3221-3231. https://doi. org/10.1007/BF02586157

[3] WorldAutoSteel (2017) Advanced High-Strength Steels Application Guidelines Version 6.0

[4] Soleimani M, Kalhor A, Mirzadeh H (2020) Transformationinduced plasticity (TRIP) in advanced steels: a review. Mater Sci Eng A 795(140023):1-42. https://doi.org/10.1016/j.mse a.2020.140023 (ISSN 0921-5093)

[5] Cabibbo M, Fabrizi A, Merlin M, Garagnani G (2008) Effect of thermo-mechanical treatments on the microstructure of micro-alloyed low-carbon steels. J Mater Sci 43(21):6857-6865. https://doi.org/10.1007/s10853-008-300 $0-8$

[6] DeArdo A, Garcia C, Palmiere E (1991) Thermomechanical processing of steel, vol 4 Heat Treating, 10th ed., Metals Handbook ASM International, pp 237-255

[7] JMatPro software v9.0 for materials properties. Sente Software. https://www.sentesoftware.co.uk/. (2018). Accessed 2018

[8] Homsher CN, Van Tyne CJ (2015) Comparison of two physical simulation tests to determine the no-recrystallization temperature in hot rolled steel plates. Mater Perform Charact 4(3):293-306. https://doi.org/10.1520/MPC20150002

[9] Dutta B, Palmiere E (2003) Effect of prestrain and deformation temperature on the recrystallization behavior of steels microalloyed with niobium. Metall Mater Trans A 34(6):1237-1247. https://doi.org/10.1007/s11661-003-02346

[10] Lin YC, Chen M-S, Zhong J (2008) Study of static recrystallization kinetics in a low alloy steel. Comput Mater Sci 44(2):316-321. https://doi.org/10.1016/j.commatsci.2008.03 .027

[11] Loveday MS, Mahon GJ, Roebuck B, Lacey AJ, Palmiere EJ, Sellars CM, van der Winden MR (2006) Measurement of flow stress in hot plane strain compression tests. Mater High Temp 23(2):85-118. https://doi.org/10.1179/mht.2006.006

[12] Hinton JS (2006) Laboratory simulation of microstructural evolution in AISI 430 ferritic stainless steel during the steckel mill process. $\mathrm{PhD}$ Department of Engineering Materials. The University of Sheffield

[13] Cui Z (2016) Thermomechanical processing of structural steels with dilute niobium additions. $\mathrm{PhD}$ Department of Engineering Materials. The University of Sheffield

[14] Advanced metals processing - Research Centres - Materials Science and Engineering. University of Sheffield. accessed in 2019. https://www.sheffield.ac.uk/materials/centresandfac ilities/metalsprocessing.

[15] Sun L (2012) The effects of strain path reversal on austenite grain subdivision, recrystallisation and phase transformations in microalloyed steel. PhD Department of Engineering Materials. The University of Sheffield

[16] Homsher C (2013) Determination of the non-recrystallization temperature (TNR) in multiple microalloyed steels. Master of Science, Colorado school of mines

[17] Zhao S, Wei D, Li R, Zhang L (2014) Effect of cooling rate on phase transformation and microstructure of $\mathrm{Nb}-\mathrm{Ti}$ microalloyed steel. Mater Trans 55(8):1274-1279. https://d oi.org/10.2320/matertrans.M2013395

[18] Mintz B, Banerjee JR, Banks KM (2011) Regression equation for Ar3 temperature for coarse grained as cast steels. Ironmak Steelmak 38(3):197-203. https://doi.org/10.1179/ 030192310X12827375731429

[19] Yuan X, Liu Z, Jiao S, Ma L, Wang G (2006) The onset temperatures of gamma to alpha phase transformation in hot deformed and non-deformed $\mathrm{Nb}$ microalloyed steels. ISIJ Int 46(4):579-585

[20] Roebuck B, Lord JD, Brooks M, Loveday MS, Sellars CM, Evans RW (2006) Measurement of flow stress in hot axisymmetric compression tests. Mater High Temp 23(2):59-83. https://doi.org/10.1179/mht.2006.005

[21] Ebrahimi GR, Momeni A, Kazemi S, Alinejad H (2017) Flow curves, dynamic recrystallization and precipitation in a medium carbon low alloy steel. Vacuum 142:135-145. h ttps://doi.org/10.1016/j.vacuum.2017.05.010

[22] Palmiere EJ, Garcia CI (1996) DeArdo AJ (1996) The influence of niobium supersaturation in austenite on the static recrystallization behavior of low carbon microalloyed steels. Metall Mater Trans A 27A:951-960

[23] Deardo AJ (2003) Niobium in modern steels. Int Mater Rev 48(6):371-402. https://doi.org/10.1179/ 095066003225008833

[24] Standard Test Method for Determining Volume Fraction by Systematic Manual Point Count (2019). ASTM E562-19:1-7. ASTM International 
[25] Neerajagarwal, Chaudhari GP, Nath SK (2013) Fine grained dual phase steel by thermomechanical Processing. Int J Appl Res Mech Eng 3(1):22-25

[26] Buchmayr B, Degner M, Palkowski H (2018) Future challenges in the steel industry and consequences for rolling plant technologies. BHM 163(3):76-83. https://doi.org/10. 1007/s00501-018-0708-x
[27] Nasiri Z, Ghaemifar S, Naghizadeh M, Mirzadeh H (2021) Thermal mechanisms of grain refinement in steels: a review. Met Mater Int 27:2078-2094. https://doi.org/10.1007/s1254 0-020-00700-1

Publisher's Note Springer Nature remains neutral with regard to jurisdictional claims in published maps and institutional affiliations. 